\title{
Plummer Vinson Syndrome in an Adolescent Male: A Rare Case
}

\author{
Shivaramakrishna Babji N ${ }^{1 *}$ and Vijayalakshmi $\mathrm{B}^{2}$ \\ ${ }^{1}$ Department of Pediatrics, PK Das Institute of Medical Sciences, India \\ ${ }^{2}$ Department of Pediatrics, NRI Medical College, India
}

*Corresponding author: Shivaramakrishna Babji N, Associate Professor, Department of Pediatrics, PK Das Institute of Medical Sciences, Vaniamkulam, Kerala, India

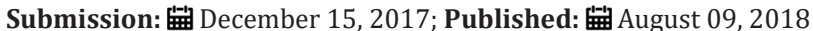

\begin{abstract}
Plummer-vinson syndrome (PVS) is defined by the classic triad of dysphagia, iron deficiency anemia and esophageal web(s) [1]. The dysphagia is usually painless and intermittent or progressive over years, limited to solids and sometimes associated with weight loss [1]. Furthermore, it is characterized by glossitis, angular cheilitis and koilonychia (spoon shaped finger nails or brittle nails) [2]. Most of the patients affected are middle aged women and it is very rare in childhood and adolescence [3,4]. One of the most important clinical aspects of PVS is its association with upper alimentary tract cancers especially squamous cell carcinoma [1].
\end{abstract}

Keywords: Plummer-vinson syndrome; Adolescent boy; Iron deficiency anemia; Esophageal web; Balloon dilatation

\section{Case Report}

A sixteen year old boy presented with symptoms of difficulty in swallowing, fatigue, progressive breathlessness along with loss of appetite and weight over a two year period. Dysphagia was slowly progressive and mainly limited to solid foods. Breathlessness was initially present during exertion, now progressed to daily routine activities. On examination the child had severe pallor, koilonychias, angular cheilitis and a just palpable spleen. Child's weight was $36 \mathrm{kgs}$ (centile) and height $148 \mathrm{cms}$ (centile). BMI was 16.8. Laboratory evaluation revealed haemoglobin level of $4.3 \mathrm{gm} / \mathrm{dl}$, MCV $55 \mathrm{fl}$ (80.7-95.5), MCH10pg (27.2-33.5), MCHC 19\%, serum iron 11ig/dl (59-158), transferring saturation of $1.8 \%$ and ferritin level $26.9 \mathrm{ng} /$ $\mathrm{ml}(30-400)$ [3]. All these were suggestive of severe iron deficiency anemia. Stool for occult blood was negative, sickle cell test negative. Serology for viral markers was non reactive. PT and aPTT with INR were within normal limits. $\mathrm{Hb}$ electrophoresis done was normal. Peripheral smear revealed microcytic hypochromic anemia. Reticulocyte count was ----. Bone marrow aspiration cytology revealed moderate degree of erythroid hyperplasia with normal myelopoeisis and normal maturation. Mega-karyopoesis was also normal and there was no evidence of abnormal cells. Upper GI endoscopy revealed presence of a post cricoids web in the cervical esophagus Figure 1.

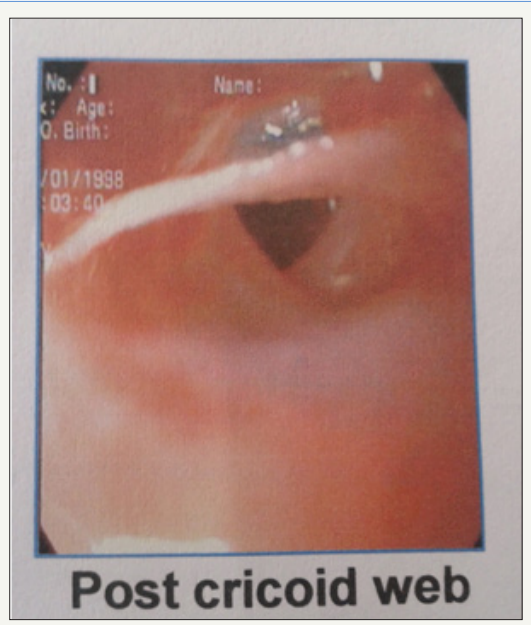

Figure 1: 
The scope could not be passed beyond the level of the web. Endoscopic balloon dilatation was done by surgical gastroenterologist subsequently, following which endoscope could be passed beyond the esophagus up to the duodenum. Child had received 3 units of packed cell transfusion during his stay in the hospital and was administered on oral elemental iron at $6 \mathrm{mg} / \mathrm{kg} /$ day. At the end of 1 month of therapy, fatigue and Dysphagia disappeared. Child started gaining weight and his general condition was good with no complaints of Dysphagia. Repeat haemoglobin was $10.3 \mathrm{mg} / \mathrm{dl}$ with an MCV of $76 f l$.

\section{Discussion}

PVS presents as a classic triad of dysphagia, upper esophageal web(s) and iron deficiency anemia. Most of the patients are middle aged women in the age group of 40-70 years. It is thought to occur by blood losses from menstruation and pregnancies. Its occurrence in childhood and adolescence is quite rare [5]. To our knowledge only 11 cases have been reported in English literature till now [4]. Symptoms resulting from anemia such as pallor, fatigue and weakness may dominate the clinical picture. In our case pallor, fatigue and dysphagia were the presenting symptoms past 2 years.

\section{Pathogenesis}

Exact mechanism not known, most probable mechanism is iron deficiency. Theory is based on rapid losses of iron dependant enzymes due to its high cell turnover. Reduction of these enzymes may cause mucosal degenerations, atrophic changes and web formation.
Studies done by Dantos and Miranda showed that iron deficiency decreased the contraction amplitude of the esophageal muscle, resulting in motility impairment in the form of slower transit time of proximal and middle parts of lower esophagus [5]. Lack of recurrence following balloon dilatation and iron therapy also support this theory. Other theories are the genetic predisposition, malnutrition and auto immunity. Celiac disease, thyroiditis and rheumatoid arthritis have been reported with PVS.

\section{Conclusion}

To conclude though PVS is rare especially in childhood, any child presenting with dysphagia and iron deficiency anemia should be investigated for PVS. The prognosis is good, except for possibility of malignant transformation. Hence regular follow up is necessary.

\section{References}

1. Anthony R, Sood S, Strachan DR, Fenwick JD (1999) A case of plummervinson syndrome in childhood. Journal of Pediatric Surgery 34(10): $1570-1572$

2. Hoffman RM, Jaffe PE (1995) Plummer-Vinson syndrome. A case report and literature review. Arch Intern Med 155(18): 2008-2011.

3. Hasan S, Khan NI, Siddiqui A (2013) Plummer vinson syndrome-A premalignant condition-an overview of literature. Journal of Medical and Dental Sciences 1(1): 28-30.

4. Bakshi SS (2015) Plummer vinson syndrome-is it common in males? Arquivos de Gastroenterologia 52(3): 250-252.

5. Mahesh CG (2015) Plummer vinson syndrome in males: a rare case. Medica Innovatica 4(2): 41-42.
Creative Commons Attribution 4.0

International License

For possible submissions Click Here
Submit Article

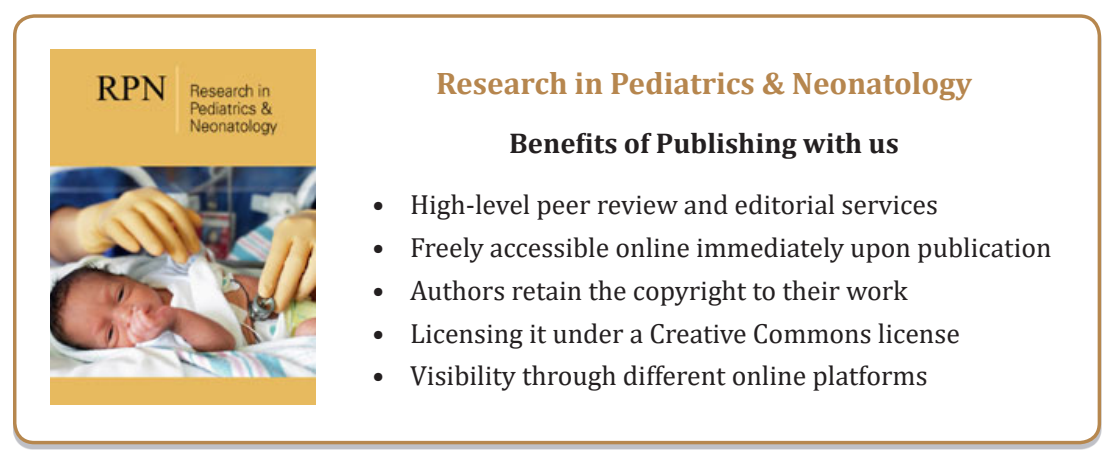

